\title{
A Discussion on Improvement of the Overall Quality of Project Management Major Students Effectively Based on Case-based Teaching Method
}

\author{
Liming Wu , Qian Liu \\ Collage of Hydraulic and Environmental \\ China Three Gorges University \\ Yichang, China \\ E-mail: wlming@ctgu.edu.cn
}

\begin{abstract}
According to the features of the hydraulic project cost management, we analyze the application of Case-based Teaching Method in the experiments of the hydroponic project cost. Case-based Teaching Method require students to combine theory and practice together, obtain tacit knowledge, develop teamwork spirit and improve their overall quality through self-presentation, mutual communication and cooperation among them.
\end{abstract}

Keywords- cost of hydraulic project; experimental teaching; case;cultivation;capacity and quality

\section{INTRODUCTION (HEADING 1)}

Project management major originated in the 1980s in China and it is relatively new. Over 200 universities and colleges offer this major after the adjustment of the undergraduate course catalog of the Ministry of Education in 1998. The rapid development of this major is due to the market demand for project management. Project management major was established relatively early in CTGU and we promotes the all-round moral, intellectual, physical and aesthetic development of the student to meet the need of socialist modernization, combined with the geographical advantage, adhere to the "Hydro" featuring.

Facing the fierce competition in the talent market, how to educate high-quality talents not only highlight the professional characteristics, but also adapt to the need of the times, is an urgent and realistic subject placed in front of the university teachers.

Practical ability of students of the project management major is an important indicator to measure the quality of talent training. Cost of hydropower engineering experiment is an important part of the project management major practice teaching and is an effective mean to cultivate students' practical ability. Introducing case-based teaching under the premise of lecture method in experimental teaching, can make up the defects of traditional teaching methods, and contribute to the training of overall quality of the students.

\section{CASE-BASED TEACHING}

Case-based teaching, also known as case teaching method, first proposed by the ancient Greek philosopher Socrates and was a mean to discuss issues ${ }^{[1]}$. It was firstly used as a teaching method by Dr. Copeland in Business Administration teaching at Harvard Business School in 1910. Case-based teaching has been utilized for a long time in law and medicine, but the utilization is not long in the field of management science. Case-based teaching is still in its infancy in theory and practice in China.

Our teachers have to give more attention and research into Case-based teaching.

There are many different understandings and interpretations of Case-based teaching, two typical definitions are: (1) Case-based teaching means according to the needs of the teaching objectives, the teachers explain a case and organize students to discuss it so that the students can learn from actual case, understand and master the general laws, principles, methods and operate the experiment.

(2) Case-based teaching refers to the classroom teaching process that all cases are based on real events. In order to get a elicitation teaching method, students can express their views by analyzing and discussing.

From the above definition is not difficult to find out the main features of Case-based teaching method: Firstly, it is a teaching method takes case as carrier. This is the most prominent feature of Case-based teaching and is the key difference from other methods.

Secondly, in this method the students are the dominant, the teachers should actively guide and inspire the students. Thirdly, all analysis and discussion are based on specific teaching objectives. The significance of applying Case-based teaching method is:

(1) Case-based teaching method is an effective way to get knowledge for students. Just as the American scholar Geke said in his article: Clever is not told. Compared with lecture method, Case-based teaching method get rid of the passive digestion and receive of knowledge, it combines boring theories with practical problems to arousing the students' interest and activating their thinking ability.

(2) The overall quality of students can be greatly improved through cases analysis and discussion. The students have a lot of autonomy to think, analyze and judge independently. The students not only acquire knowledge, but also develop their abilities to analyze, make decision, express, manage time, interpersonal, create, etc.

(3) The students can get the internalized knowledge through Case-based teaching. They can put themselves in the actual situation which based on the real situations and raise various possible solutions to problems. This is a training for the students before job, the students can make these knowledge to be their own and integrate them through the accumulation of these experiences. ${ }^{\text {3] }}$

(4) Case-based Teaching, in part, makes up for the 
lack of teaching training base. It is impossible for the enterprises which signed cooperation agreements with colleges and universities to provide students with temporary internships. ${ }^{[4]}$ And the training of students can not depend on the enterprise practice solely. Because the time of the enterprise practice is limited so that students can not get comprehensive training of a special course. Case-based Teaching enables the students to master the techniques or solution for the problems in the class which to some extent can compensate for the training constraints defect.

\section{THE QUALITY REQUIREMENTS OF THE ENGINEERING MANAGEMENT MAJOR}

The objective of CTGU is to cultivate practical management talents who grasp the basic knowledge of engineering and economics, master the theories and methods of modern project management, in the domestic outside the construction field in engineering management, application management personnel.

The core of the university education is the overall quality improvement. And for engineering management major , expressed in follows:

(1) Learning capability. Engineering management personnel should have the ability to acquire knowledge. They must have serious and scientific research ability to discover problems and solve them in the practice of engineering management.

(2) Communication skills. Cause the information of project cost and transmission of it concern the interests of all parties, good communication skills helps to promote the work. Communication skill is important for practitioners in the practice of project cost management. Such as the drafting of the contract, the expression should be logic, accurate or that would bring the performance of the contract to endless disputes.

(3) Organizational capacity and administrative capacity. Project cost management is an important team in the construction engineering. In order to realize the goal, the team leader and team member should have stronger organizational capacity and administrative capacity.

(4) Reactive capacity. On one hand, it is determined by the features of the construction projects. The construction of hydropower project affected by the natural, social and other factors greatly, and the practitioners play important roles in solving different new problems; on the other hand, fast response capability is requested in solving the problems in bidding, variation of the contract price, measurement and payment and claims within a limited time.

(5) Innovation ability. Innovation can promote the works of Project Cost Management effectively.

\section{HYDROPOWER PROJECT COST EXPERIMENT HAS AN IMPORTANT POSITION IN THIS MAJOR}

We adhere to and improve "Class teaching + Laboratory Training + Social practice "mode, and carry out the basic quality training of theory study, experiment and curriculum design, graduation practice. The project cost experiments we offer are: hydropower project cost experiment, training of the software construction project cost management, quota test, etc. Hydropower project cost experiment is mainly for hydropower engineering industry and it is an expertise experiment which has the features of professional, practical, and operational.

\section{USING CASE-BASED TEACHING IN EXPERIMENT CAN IMPROVE THE OVERALL QUALITY OF STUDENTS EFFECTIVELY}

Most of hydroelectric stations are located in the remote mountains and valleys. The features of hydroelectric project cost management are great influence factors, powerful policies, complex evaluation process and these features are determined by different nature situations of each projects. It is essential and urgent to apply Case-based teaching in hydraulic project cost experiment. The following objectives can be achieved by applying Case-based teaching:

(1) Improve the capability to linking theory with practice. Hydraulic project cost experiment is a practical course combined with budget software based on the courses of "hydroelectric projects technology", "evaluation of hydraulic project". It is said that the specialized courses of project management major is theoretical and different from the reality of the project evaluation. The applying of Case-based teaching is our hope to find a way out of this dilemma ${ }^{[5]}$. The case is the reproduction of the project evaluation practice. The capabilities of problem-analyzing, problem-solving, decision-making will be greatly improved by using theory to solve practical problems.

(2) Develop the teamwork spirit and improve the overall quality of student. In Case-based teaching, students have to participate in discussions and communication and express their views and opinions. Meanwhile, Case-based teaching relies on the cooperation among students particularly. The learning effect engendered in such a mutually supportive team is better than that alone. Teamwork spirit can be developed gradually in this practice environment.

(3)Acquire "Tacit Knowledge". Tacit knowledge is a philosophy concept put forward by Michael Polanyi in 1958, from his opinion there are two kinds of human knowledge. One is "explicit knowledge" which can be transmitted through normal verbal communication. Another is "tacit knowledge" which is opposite to "explicit knowledge" and it refers to the knowledge that we know but impossible to speak out. Cost management is a soft management; it is scientific and artistic which has connection with personal insight, intuition, perception, experience, skills, knack, values, and teamwork. In the experiment, through the mutual exchange of information, members of the team receive information then apperceive, understand and internalize it to create new ideas (explicit knowledge).And this new idea is becoming the tacit knowledge of other members. The innovation and 
application of knowledge is the ultimate goal of knowledge management. Case-based Teaching provided such a practice opportunity to help individuals comprehend and learn tacit knowledge in the process of thinking, discussing, and arguing. ${ }^{[5]}$

\section{CONCLUSION}

In order to cultivate good overall quality students, it is an effective way to apply Case-based teaching in hydraulic project evaluation experimental teaching based on the importance of the hydropower project evaluation experiment and the close connection between experiment and practice. In addition, from the feedback of the graduates and survey units, they think that the learning of theory and expertise and practice exercising an invisible, formative influence on them. Therefore, it is an effective way to apply Case-based teaching in hydraulic project evaluation experimental teaching.

\section{ACKNOWLEDGMENT}

Teaching and research project: 2012 Teaching and research project of Three Gorges University "Research on Case-based and progressive hydraulic project cost experimental teaching mode"(J2012041), "Research on curriculum system of Engineering Management Major based on hydraulic features".

\section{REFERENCES}

[1] Yufa Ouyangn, Case-based Teaching Method - the Feasible Choice for Teacher,Continuing Education ,2007 (8)

[2] Fengguang Guo ,Analysis of Misunderstanding and Execution of Case-based Teaching Method, China Electronic Education, 2007 (9)

[3] Jinzhou Zheng, Case-based Teaching Guide, East China Normal University Press, 2000.06

[4] Minghui Hu, A Discussion on the Case-based Teaching Mode in Vocational Colleges, Journal of Wuhu Institute of Technology, 2011 (1)

[5] Xu Dan, Case-based Teaching and Engineering Management Professional Training, Journal of Jiangxi University of Finance and Economics, 2006 (3) 